Article

\title{
Highly Efficient Flame Retardant Hybrid Composites Based on Calcium Alginate/Nano-Calcium Borate
}

\author{
Zhenhui Liu ${ }^{1,+}$, Zichao Li ${ }^{2,+}$, Xihui Zhao ${ }^{1}$, Lei Zhang ${ }^{1}$ and Qun Li ${ }^{1, * \text { (D) }}$ \\ 1 College of Chemistry and Chemical Engineering, Qingdao University, Qingdao 266071, China; \\ 2016020405@qdu.edu.cn (Zh.L.); zhaoxihui@qdu.edu.cn (X.Z.); 2017020832@qdu.edu.cn (L.Z.) \\ 2 College of Life Sciences, Qingdao University, Qingdao 266071, China; zichaoli@qdu.edu.cn \\ * Correspondence: qunli@qdu.edu.cn; Tel.: +86-532-8595-0705 \\ + These authors contributed equally to this work.
}

Received: 5 May 2018; Accepted: 4 June 2018; Published: 6 June 2018

\begin{abstract}
Hybrid composites with low flammability based on renewable calcium alginate and nano-calcium borate were fabricated using an in situ method through a simple, eco-friendly vacuum drying process. The composites were characterized by X-ray diffractometry (XRD), Fourier transform infrared spectrum (FTIR), scanning electron microscopy (SEM), and thermogravimetric analysis (TGA). The combustion behavior and flammability of the composites were assessed by using the limiting oxygen index (LOI) and cone calorimetry (CONE) tests. The composites showed excellent thermal stability and achieved nonflammability with an LOI higher than 60. Pyrolysis was investigated using pyrolysis-gas chromatography-mass spectrometry (Py-GC-MS) and the results showed that fewer sorts of cracking products were produced from the hybrid composites compared with the calcium alginate. A possible thermal degradation mechanism of composites was proposed based on the experimental data. The combined results indicate that the calcium borate had a nano-effect, accumulating more freely in the hybrid composites and contributing significantly to both the solid phase and gas phase, resulting in an efficient improvement in the flame retardancy of the composites. Our study provides a novel material with promising potentiality for flame retardant applications.
\end{abstract}

Keywords: calcium alginate; nano-calcium borate; flame retardancy; pyrolysis; thermal degradation

\section{Introduction}

The energy crisis triggered by excessive consumption of fossil resources has inspired humans to search for chemicals and fuels which are sustainable and renewable [1]. Biomass represents the most abundant renewable carbon resource on Earth, and has attracted enormous attention from researchers in the recent decades [2,3]. Sodium alginate, as a natural polysaccharide, is an important class of biomass existing both in cell walls of brown algae and in soil bacteria as capsular saccharides $[4,5]$. Its characteristic structure consists of two random arranged uronic acids, $\beta$-D-mannuronic acid (M block), and $\alpha$-L-guluronic acid (G block) [6-8]. The $M$ and $G$ possess different proportions and order depending on the source of alginic acid [9]. As the material is considered to be non-toxic, biocompatible, and biodegradable [10-14], it is widely used in biomedical materials for drug delivery and immobilization of microorganisms [15-18]. The $\mathrm{G}$ residues in alginate can gelate with divalent metal ions such as $\mathrm{Ca}^{2+}$ to form calcium alginate according to the popular egg-box model theory [19-22]. As calcium alginate has been reported as having limiting oxygen index (LOI) value of 48.0 and a peak heat release rate of $4.99 \mathrm{~kW} / \mathrm{m}^{2}$ [23], it can be developed as a promising material with flame-retardant properties $[24,25]$. 
Nano-microparticle composites, with desirable physicochemical properties, high mechanical strength, and efficiently enhanced flame retardancy, have generated plenty of attention so far [26-29]. Liu reported that the $2 \mathrm{CaO} \cdot \mathrm{B}_{2} \mathrm{O}_{3} \cdot \mathrm{H}_{2} \mathrm{O}$ nanomaterials [30] and $\mathrm{Ca}_{2} \mathrm{~B}_{2} \mathrm{O}_{5} \cdot \mathrm{H}_{2} \mathrm{O}$ nanostructures [31] showed ideal flame-retardant properties with large specific surface area and low surface free energies. Lewin demonstrated that the nano-micropaticles in the composites can easily accumulate at the surface of combustion area and efficiently improve the stability of the polymers [32-34].

The aforementioned reports indicate that both the nano-calcium borate and calcium alginate show promise as low-flammability materials. To further improve the flame-retardant properties of calcium alginate, synergistic systems with other flame retardants were generally employed [11]. In this study, the uniform calcium alginate/nano-calcium borate composites were prepared through a simple and environmentally friendly method without usage of dispersant, through which the flame retardancy was improved by the nano-calcium borate composites as compared calcium alginate alone, and costs and time were also saved. To the knowledge of the authors, this is the first report on the preparation of hybrid composites using borate and sodium alginate as precursors via an in situ method, which is advantageous in comparison with traditional methods such as physical blends or chemical combination [35]. Furthermore, the improved flame-retardant properties and thermal stabilities of the prepared calcium alginate composites were tested, and the mechanism was proposed based on the experimental data.

\section{Materials and Methods}

\subsection{Materials}

Sodium alginate was purchased from Guangfu Fine Chemical Research Institute (Tianjin, China). Calcium chloride and borax (sodium tetraborate decahydrate) were obtained from Kermel Chemical Reagent Co., Ltd. (Tianjin, China). All the other reagents were purchased from Sinopharm Chemical Reagent Co., Ltd. (Shanghai, China) and were of analytical grade.

\subsection{Preparation of the Calcium Alginate/Nano-Calcium Borate Composites}

The preparation process of the calcium alginate/calcium borate is shown schematically in Scheme 1. Borax $(1.25 \mathrm{~g})$ was blended with $250 \mathrm{~mL}$ distilled water. The solution was stirred at $70{ }^{\circ} \mathrm{C}$ for $5 \mathrm{~min}$. Then, $10 \mathrm{~g}$ of sodium alginate was slowly added into borax solution with constant stirring. The obtained transparent gel was moved to glass utensil and immersed in $70 \%(\mathrm{~m} / \mathrm{v})$ calcium chloride solution after the gel shape was fixed. The $\mathrm{pH}$ of the solution was adjusted to 10 and kept at $30{ }^{\circ} \mathrm{C}$ for $10 \mathrm{~h}$ to ensure that the gel was cross-linked completely. Finally, the material was washed in distilled water, and then dried at $55^{\circ} \mathrm{C}$ to obtain the calcium alginate/nano-calcium borate (CAB) composites. The preparation of calcium alginate (CA) was similar to that of $\mathrm{CAB}$, while the use of borax was excluded in the process.

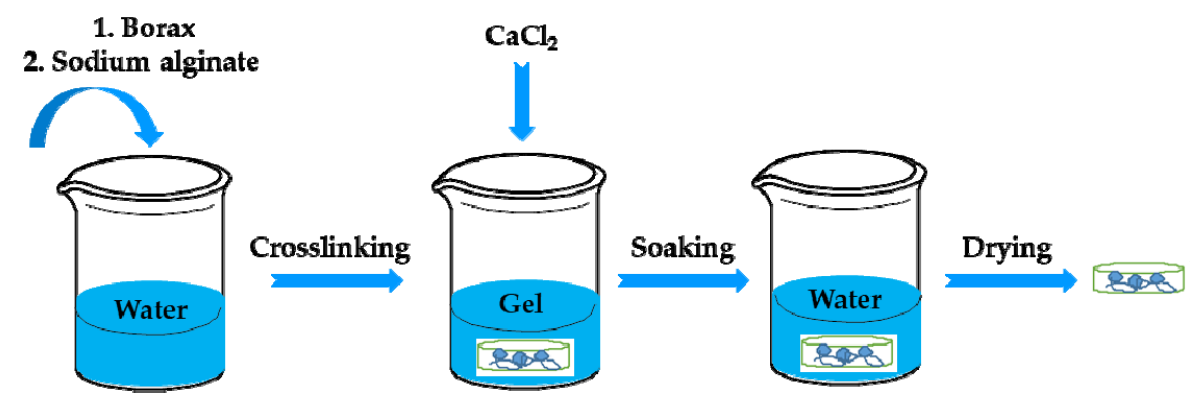

Scheme 1. Preparation of calcium alginate/nano-calcium borate (CAB) composites. 


\subsection{Measurements and Characterizations}

\subsubsection{Limiting Oxygen Index (LOI)}

The LOI tests were performed on a JF-3 type instrument (Jiangning Analytical Instrument Co., Nanjing, China) according to standard method ISO 4589-1:1996. Specimens of dimensions $100 \mathrm{~mm} \times$ $40 \mathrm{~mm} \times 2 \mathrm{~mm}$ were used for all the tests.

\subsubsection{Vertical Burning Rate (UL-94)}

Vertical burning test was performed by using a CZF-2 vertical burning test instrument (Jiangning Analytical Instrument Co., Nanjing, China) according to ISO 5660 with sheet dimensions of $130 \mathrm{~mm} \times$ $13 \mathrm{~mm} \times 2 \mathrm{~mm}$.

\subsubsection{X-ray Diffractometry (XRD)}

XRD of the prepared samples and the cracking residues (heated in tube furnace with a heating rate $5{ }^{\circ} \mathrm{C} / \mathrm{min}$ ) was performed on an X-ray diffractometer (D/Max-RB, Rigaku Inc., Tokyo, Japan) equipped with $\mathrm{Cu}-\mathrm{K} \alpha$ radiation at room temperature. The samples were scanned up to $90^{\circ}$ in $2 \theta$ in a continuous mode.

\subsubsection{Fourier Transform Infrared (FTIR)}

The chemical bonds in the samples and the cracking residues were determined by the FTIR spectroscopy (NICOLET iS50, Thermo Fisher Scientific Inc., Waltham, MA, USA) within the wave number range of $4500-500 \mathrm{~cm}^{-1}$.

\subsubsection{Scanning Electron Microscopy (SEM)}

The morphology and microstructure of the samples and the residues were examined by a SEM (JSM 6390LV, JEOL Inc., Tokyo, Japan). All the sample surfaces studied were sprayed with gold to avoid charging under the electron beam.

\subsubsection{Thermogravimetric Analysis (TGA)}

TGA was performed on a thermogravimetric analyzer (TG 209, NETZSCH Geraetebau GmbH, Selb, Germany) with a heating rate of $10{ }^{\circ} \mathrm{C} / \mathrm{min}$. The prepared 5-mg sample was examined with a flow rate of $50 \mathrm{~mL} / \mathrm{min}$ from room temperature to $1000^{\circ} \mathrm{C}$ in air and $\mathrm{N}_{2}$ atmosphere, respectively.

\subsubsection{Cone Calorimetry (CONE)}

The combustion behavior of the samples was measured by a cone calorimeter device (M1354, Fire Testing Technology Ltd., East Grinstead, UK) according to ISO 5660, under an external heat flux of $50 \mathrm{~kW} / \mathrm{m}^{2}$. All samples with dimensions $100 \mathrm{~mm} \times 100 \mathrm{~mm} \times 2 \mathrm{~mm}$ were wrapped in aluminum foil and placed in the horizontal position in a box with the same dimension.

\subsubsection{Pyrolysis-Gas Chromatograpgy-Mass Spectrometry (Py-GC-MS)}

Py-GC-MS was performed using a fast pyrolysis analyzer (CDS 5200, CDS Analytical Inc., Oxford, MS, USA) coupled with a GC-MS (Clarus 680GC-SQ8MS, PerkinElmer, Inc., Shelton, CT, USA). The pyrolysis temperature was set at 200,400 , and $750{ }^{\circ} \mathrm{C}$, and the carrier gas was He. The GC temperature program started at $50{ }^{\circ} \mathrm{C}$ and then increased to $300^{\circ} \mathrm{C}$ within $15 \mathrm{~min}$. The product of the compounds can be identified by the characterized GC/MS spectrums, according to comparison with the National Institute of Standards and Technology (NIST) library and other reports. 


\section{Results and Discussion}

\subsection{LOI and UL-94}

The flame retardancy of CAB and CA was estimated by LOI and UL-94 vertical burning tests, and the results are listed in Table 1. It can be seen that both CAB and CA exhibited notable flame-retardant properties with high LOI values. It can be seen that both CAB and CA cannot be ignited and exhibit notable flame-retardant properties with high LOI values. Moreover, it can be noted that the LOI was increased from $48(\mathrm{CA})$ to over $60(\mathrm{CAB})$ by the introduction of $4 \%$ borax, indicating the important contribution of calcium borate to the high flame-retardant efficiency of CAB.

Table 1. Combustion parameters obtained using the limiting oxygen index (LOI) and vertical burning rate (UL-94). CA: calcium alginate.

\begin{tabular}{ccc}
\hline Samples & LOI (\%) & UL-94 \\
\hline CA & 48 & V-0 \\
CAB & $>60$ & V-0 \\
\hline
\end{tabular}

\subsection{XRD Analysis}

Figure 1 shows the XRD patterns of $\mathrm{CAB}$ and the cracking residues after heating at 350 and $700{ }^{\circ} \mathrm{C}$. It can be noted that $\mathrm{CAB}$ was a kind of polymer material displaying crystallinity. The diffraction peaks of $28.46^{\circ}$ and $31.34^{\circ}$ seen in Figure $1 \mathrm{a}$ can be assigned to $\mathrm{Ca}_{2} \mathrm{~B}_{2} \mathrm{O}_{5} \cdot \mathrm{H}_{2} \mathrm{O}$ (JCPDS PDF\# 22-0139), suggesting $\mathrm{CAB}$ was synthesized. The new peaks of $32.96^{\circ}$ can be observed from Figure $1 \mathrm{~b}$, indicating the formation of calcium carbonate (JCPDS PDF\# 33-0268). As shown in Figure 1c, the peaks of $37.41^{\circ}$ and $53.93^{\circ}$ can be attributed to the decomposition of calcium carbonate into calcium oxide (JCPDS PDF\# 82-1690) when $C A B$ was further heated to $700^{\circ} \mathrm{C}$. Moreover, the existence of the calcium borate in the composites can be noted even at the higher heating temperature.
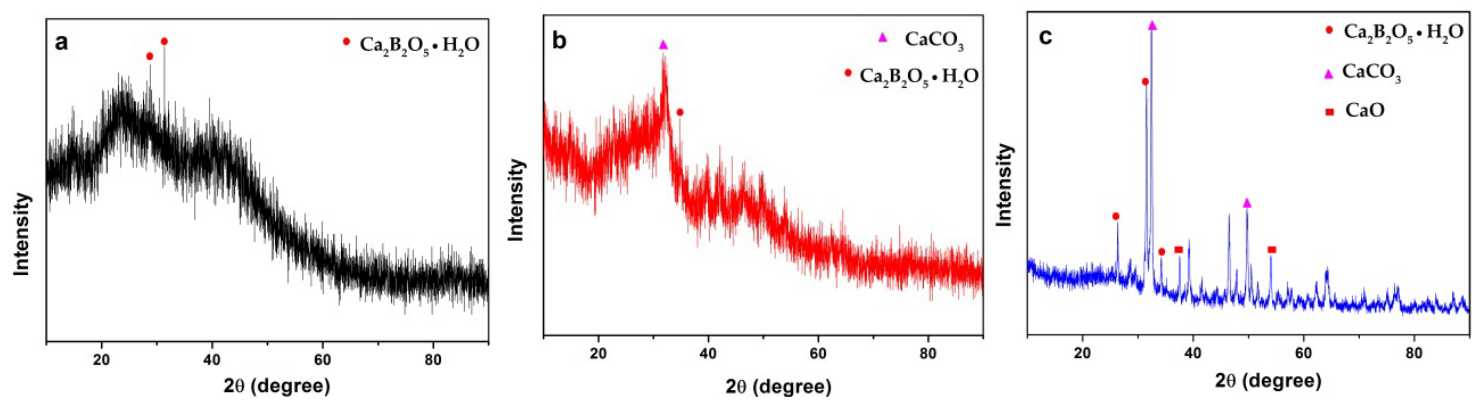

Figure 1. XRD patterns of (a) unheated $\mathrm{CAB}$; (b) $\mathrm{CAB}$ heated to $350{ }^{\circ} \mathrm{C}$; (c) $\mathrm{CAB}$ heated to $700{ }^{\circ} \mathrm{C}$.

\subsection{FTIR Analysis}

As seen in the FTIR spectra of the samples shown in Figure 2, a series of characteristic absorption peaks for CA were observed at $3285 \mathrm{~cm}^{-1}$ (O-H stretching vibration), $2915 \mathrm{~cm}^{-1}\left(-\mathrm{CH}_{2}\right), 1584 \mathrm{~cm}^{-1}$ (C=O stretching vibration) [36], $1253 \mathrm{~cm}^{-1}$ and $1429 \mathrm{~cm}^{-1}$ (assigned to the symmetric and asymmetric vibrations of -COO), $1331 \mathrm{~cm}^{-1}$ (-OH deformation vibration) [37], 1029 and $914 \mathrm{~cm}^{-1}$ (attributed to the symmetric and asymmetric vibrations of $\mathrm{C}-\mathrm{O}-\mathrm{C})$, and $816 \mathrm{~cm}^{-1}\left(-\mathrm{CH}_{2}\right.$ in plane sway vibration), respectively. Noticeably, the peak at $933 \mathrm{~cm}^{-1}$ can be assigned to the $\mathrm{B}-\mathrm{O}$ symmetric stretching, while the two peaks with similar intensities and shapes appearing at $1312 \mathrm{~cm}^{-1}$ and $1410 \mathrm{~cm}^{-1} \mathrm{can} \mathrm{be}$ ascribed to the asymmetric stretching of $\mathrm{B}-\mathrm{O}$, indicating the formation of calcium borate in $\mathrm{CAB}$, although most of other chemical groups were detected in both of the samples. 


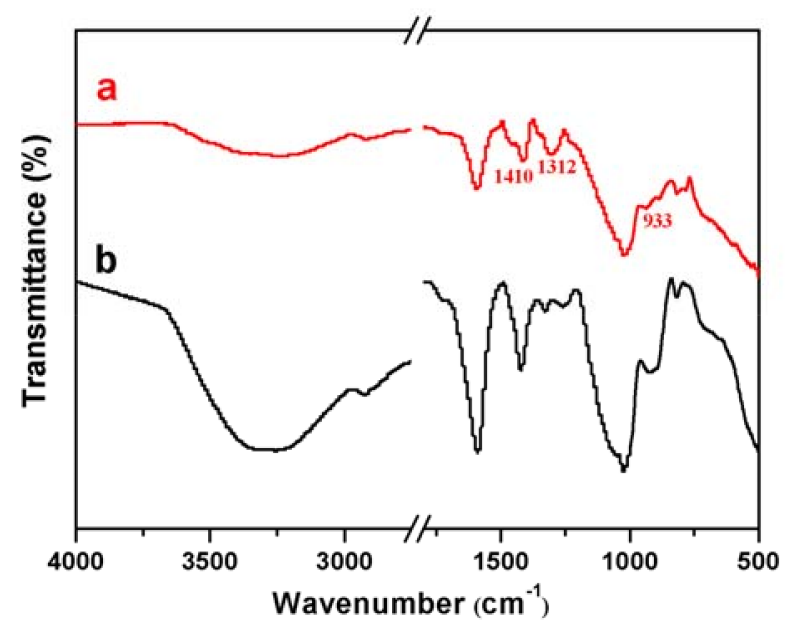

Figure 2. FTIR spectra of (a) CAB and (b) CA.

\subsection{SEM}

The SEM images of the prepared samples and the cracking residues of CAB after combustion at different temperatures are shown in Figure 3. As seen in Figure 3a, the surface with schist-like shapes of about 100-nm thickness can be observed in CA. It can be observed from Figure $3 \mathrm{~b}$ that the calcium borate was uniformly embedded in CA, and the nano-calcium borate particles were self-assembled into sphere shapes with the size of around 100-200 nm, as displayed in the inset of Figure 3b. As shown in Figure $3 c$, the nano-calcium borate particles kept their original morphology and no notable change can be observed after the $\mathrm{CAB}$ was heated to $500^{\circ} \mathrm{C}$. However, as seen in Figure $3 \mathrm{~d}$, the particles at the surface of $\mathrm{CAB}$ were changed to worm-like shapes after being heated to $700^{\circ} \mathrm{C}$, which may be a result of the calcium borate melting and loss of the modification of $\mathrm{CA}$ at the higher temperature.
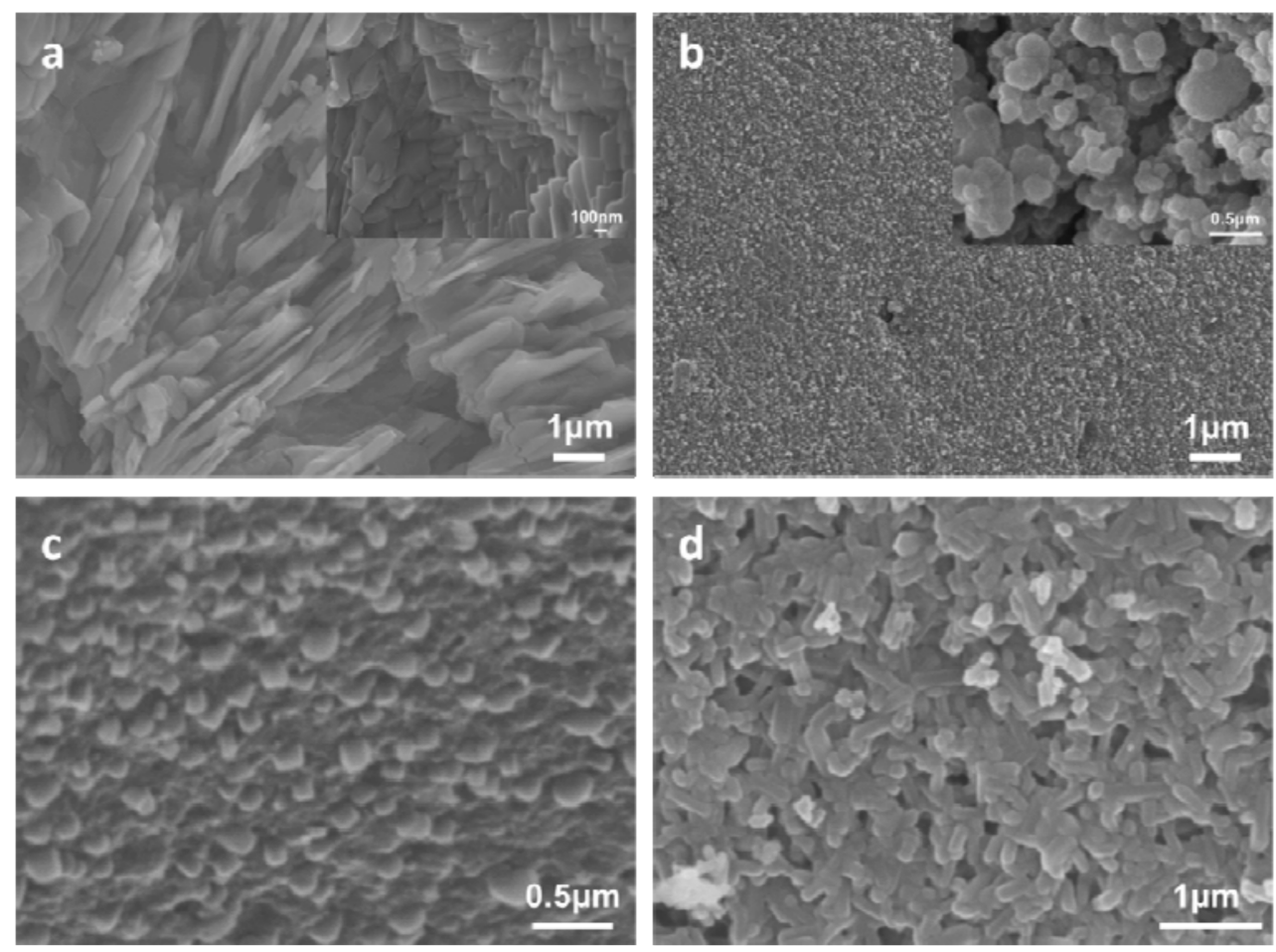

Figure 3. SEM images of (a) CA; (b) CAB; (c) CAB heated at $500{ }^{\circ} \mathrm{C}$; and (d) $\mathrm{CAB}$ heated at $700{ }^{\circ} \mathrm{C}$. The insets in $(\mathbf{a}, \mathbf{b})$ are the magnified images, respectively. 


\subsection{TGA and DTG}

\subsubsection{Thermal-Oxidative Degradation Behaviors under Air}

As seen in Figure $4 \mathrm{a}, \mathrm{b}, \mathrm{CAB}$ and $\mathrm{CA}$ exhibited similar degradation trends, with certain differences. It can be observed that the first step occurred at temperatures ranging from 50 to $230^{\circ} \mathrm{C}$, corresponding to the water desorption and for the $\mathrm{CAB}$ including the loss of crystal water in the calcium borate. The main degradation of $\mathrm{CAB}$ and $\mathrm{CA}$ occurred at $230-450{ }^{\circ} \mathrm{C}$, which can be mainly associated with the destruction of glycosidic bonds. Moreover, the performance of CAB and CA at $450-700{ }^{\circ} \mathrm{C}$ can be ascribed to the oxidation of the previously formed carbonaceous char materials. The results indicated that $C A B$ generated more residues compared with $C A$, suggesting that $C A B$ possessed better thermal-oxidative stability.
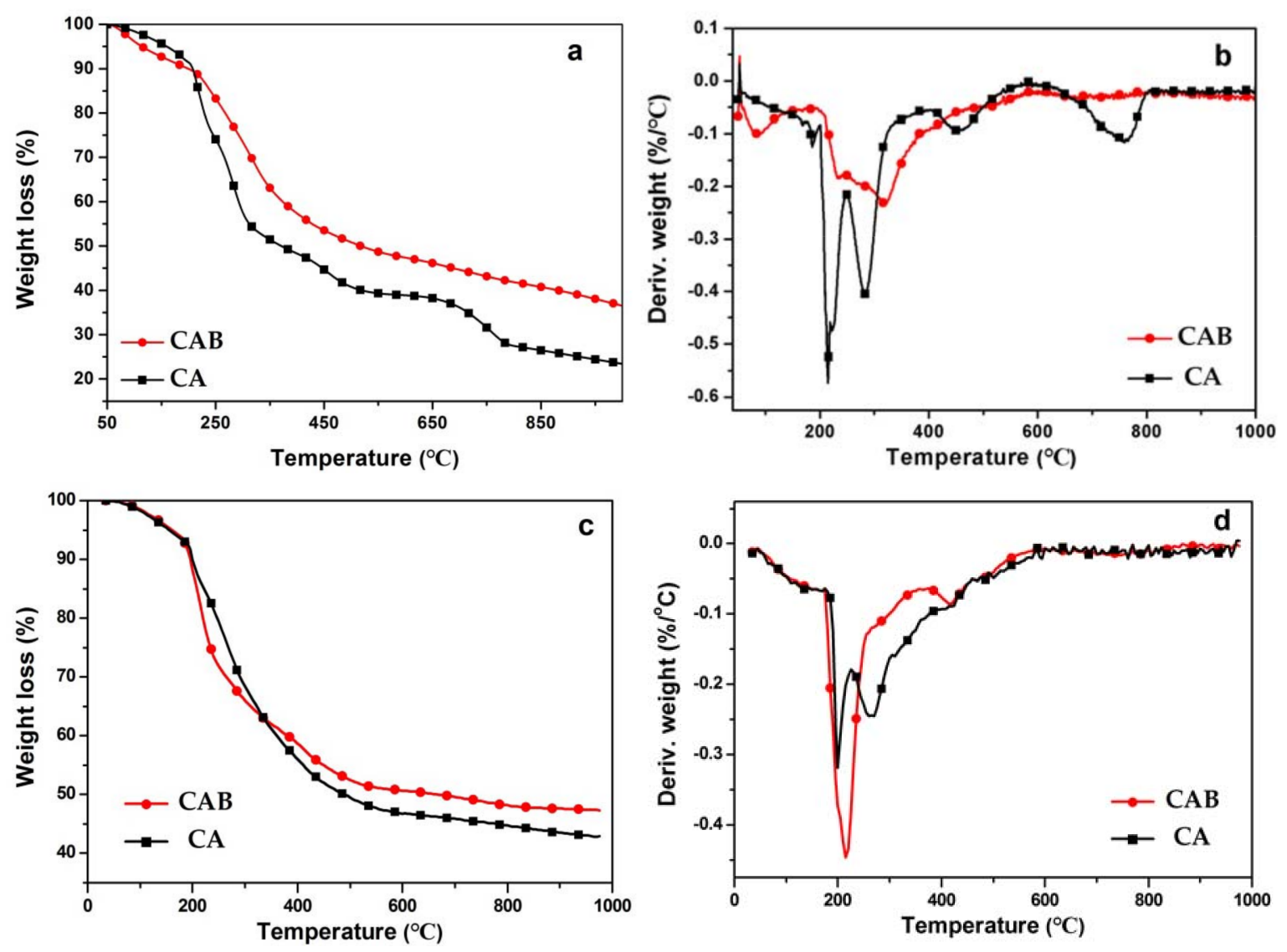

Figure 4. (a) TGA and (b) DTG curves of CAB and CA under air; (c) TGA and (d) DTG curves of CAB and $\mathrm{CA}$ under $\mathrm{N}_{2}$.

\subsubsection{Thermal Degradation Behaviors under $\mathrm{N}_{2}$}

The TG curves of $C A B$ and $C A$ in $N_{2}$ are displayed in Figure $4 c, d$, and two main stages were found based on the patterns. An about $7 \%$ weight loss of $C A B$ and $C A$ can be observed from the first stage, which may be due to the moisture evaporation from ambient temperature to $200^{\circ} \mathrm{C}$. Over $200^{\circ} \mathrm{C}$, the main weight losses for $\mathrm{CAB}$ and $\mathrm{CA}$ were observed, which can be associated with the fracture of the glycosidic bonds, and dehydration, decarboxylation, and decarbonylation of alginate. Furthermore, $\mathrm{CAB}$ showed higher weight loss than that of $\mathrm{CA}$ at the range of $200-350{ }^{\circ} \mathrm{C}$, which may be ascribed to the loss of crystal water in the calcium borate. In addition, the maximum-rate decomposition temperature of $\mathrm{CAB}\left(410^{\circ} \mathrm{C}\right)$ was higher than that of $\mathrm{CA}\left(275^{\circ} \mathrm{C}\right)$ in the second stage. This result may 
be in the reason that the calcium borate in the composites was melted and then protected the alginate from decomposition.

In addition, it seems borate can act as an endothermic cooling agent by losing its own crystal water in the gas phase at temperatures ranging from 200 to $350{ }^{\circ} \mathrm{C}$, while it melted and formed a glassy cover at the surface to shelter the material from the heat in the solid phase at the higher temperature. This indicates that the introduction of calcium borate can improve the thermal stability of CA.

TGA was performed in air and $\mathrm{N}_{2}$, respectively, to understand the effect of oxygen on the degradation for $\mathrm{CAB}$ at high temperature by comparison. The $\mathrm{TG}$ curve of $\mathrm{CAB}$ in air was in accordance with that in $\mathrm{N}_{2}$ below $200{ }^{\circ} \mathrm{C}$, indicating that the oxygen did not take part in the degradation process of $\mathrm{CAB}$ until the temperature reached $200^{\circ} \mathrm{C}$. It can be noted that $\mathrm{CAB}$ degraded much more in air than in $\mathrm{N}_{2}$, which led to the amount of the residues for $C A B$ in air was less than that in $\mathrm{N}_{2}$. The residues were relatively stable once formed under both of the atmosphere.

\subsection{CONE}

CONE is one of the most effective methods to evaluate the flame-retardant properties of the tested materials through simulating fire conditions in the real world [38,39]. It was used to study the combustion behavior of $\mathrm{CAB}$ and $\mathrm{CA}$, as displayed in Figure 5 with related data listed in Table 2 . The heat release rate (HRR) is an important parameter to characterize the fire safety and a lower HRR value indicates slower spread of fire [34]. It can be seen from Figure 5a that the HRR of CAB was much lower than that of $C A$, while $C A B$ showed a decreased peak heat release rate (PHRR) value compared to that of CA. It can be observed from Figure $5 b$ that the total heat release (THR) of the two samples increased over time. CAB showed lower values of HRR and THR, indicating it possessed better flame-retardant properties compared to $\mathrm{CA}$. This may be attributed to that the calcium borate in $\mathrm{CAB}$ produced a residue layer and acted as an insulating barrier between the fire and the material during combustion. As shown in Figure 5c, CAB produced more smoke than CA did, which may be ascribed to that the surface of CA was covered by calcium borate in the composites which could not be completely burned under the condition that the oxygen was partially insulated. Moreover, the residual amount of $\mathrm{CAB}(35.3 \%)$ was higher than that of $\mathrm{CA}(33.1 \%)$ at $360 \mathrm{~s}$. Combining the above-mentioned results, $\mathrm{CAB}$ showed better flame-retardant properties than $\mathrm{CA}$ in the CONE tests.

Table 2. Combustion parameters obtained from cone calorimetry (CONE). PHRR: peak heat release rate; THR: total heat release; TSR: total smoke release.

\begin{tabular}{ccccc}
\hline Samples & THR $\left(\mathbf{M J} / \mathbf{m}^{\mathbf{2}}\right)$ & PHRR $\left(\mathbf{k W} / \mathbf{m}^{\mathbf{2}}\right)$ & TSR $\left(\mathbf{m}^{\mathbf{2}} / \mathbf{m}^{\mathbf{2}}\right)$ & Residue $(\mathbf{\%})$ \\
\hline CA & 6.76 & 46.6 & 70.5 & 33.1 \\
CAB & 5.51 & 34.3 & 130.1 & 35.3 \\
\hline
\end{tabular}
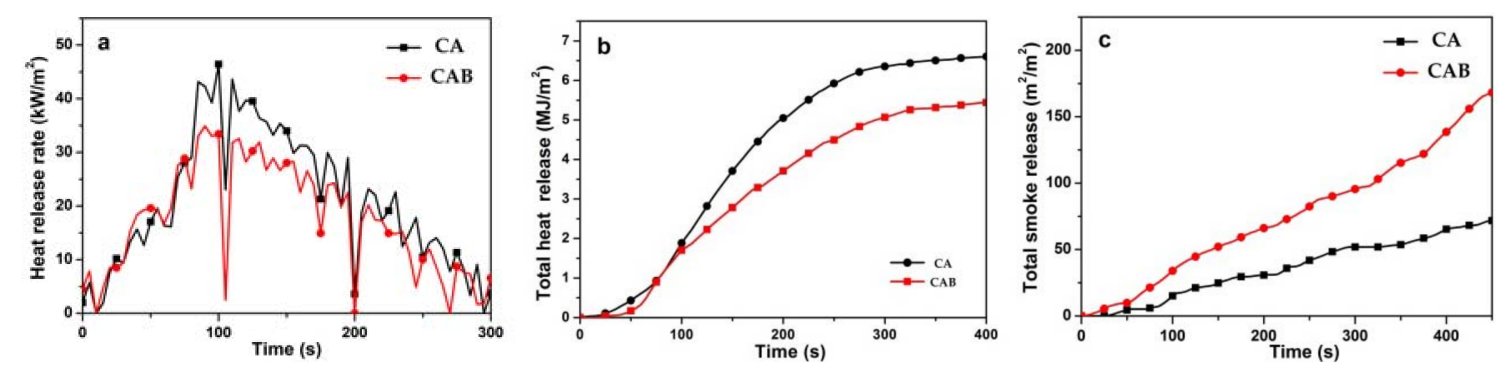

Figure 5. (a) HRR, (b) THR, and (c) TSR curves of CA and CAB changing with time.

\subsection{Py-GC-MS}

The Py-GC-MS analysis was conducted to research the main components of gaseous products of $\mathrm{CAB}$ in the pyrolysis process [40]. Most of the produced compounds were identified by comparison 
with the NIST library and listed in Table 3. Figure 6 shows the chromatograms of CAB obtained from Py-GC-MS tested at 200,400 , and $750{ }^{\circ} \mathrm{C}$, respectively. The main compounds generated at $400{ }^{\circ} \mathrm{C}$ were as follows: carbon dioxide, 2,3,4,5-tetrahydroxyvaleric acid, dimethyl ether, 2-furaldehyde, and 5 -methyl-furfural. It can be noted that the main products can be divided into four groups including carbon dioxide, organic acid (i.e., acetic acid), ketone (i.e., 2-propanone and 3-hydroxy-2-butanone), and aldehyde (i.e., acetaldehyde). Compared with the pyrolysis compounds of CA, much more ketone and aldehyde were produced in the decomposition compounds of $C A B$ [23]. It can be seen that the decomposition products of $\mathrm{CAB}$ at $750{ }^{\circ} \mathrm{C}$ were mainly aromatic hydrocarbons, alcohol, and olefin which was further decomposed, suggesting that the introduction of calcium borate exerted positive effects on the degradation process of $\mathrm{CA}$, and thus made it more resistant to the high temperature.
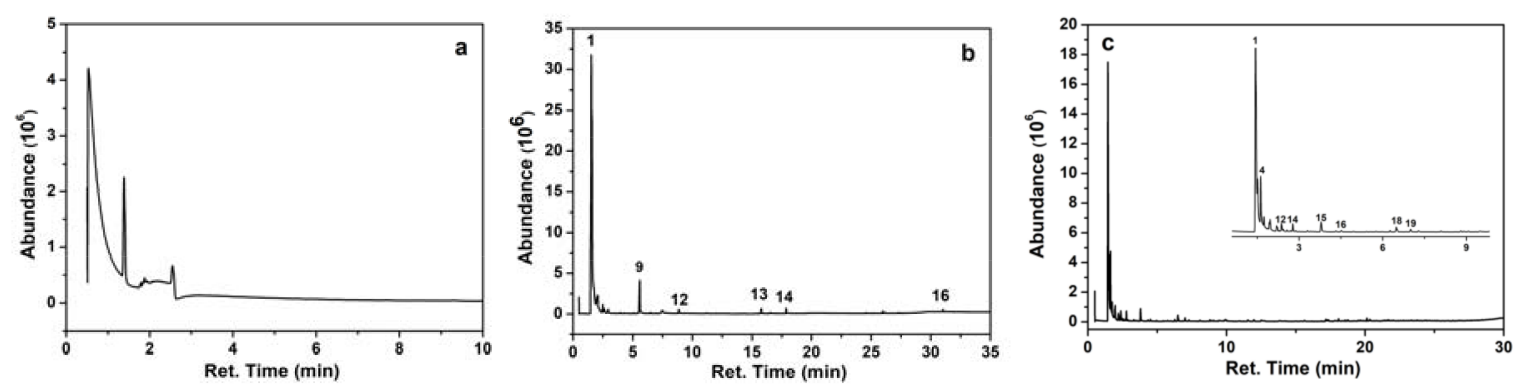

Figure 6. Py-GC-MS spectra of $\mathrm{CAB}$ at $200{ }^{\circ} \mathrm{C}(\mathbf{a}), 400{ }^{\circ} \mathrm{C}(\mathbf{b})$, and $750{ }^{\circ} \mathrm{C}$ (c). The inset in (c) is the magnified spectrum of retention time within $9.5 \mathrm{~min}$.

Table 3. Pyrolysis products of the CAB at different temperatures.

\begin{tabular}{|c|c|c|c|c|c|c|c|}
\hline \multirow{2}{*}{\multicolumn{2}{|c|}{ Molecular Structure Name of Compound }} & \multicolumn{2}{|c|}{$T=250^{\circ} \mathrm{C}$} & \multicolumn{2}{|c|}{$T=400^{\circ} \mathrm{C}$} & \multicolumn{2}{|c|}{$T=750^{\circ} \mathrm{C}$} \\
\hline & & \multirow{2}{*}{$\begin{array}{c}\text { Time } \\
0.53\end{array}$} & \multirow{2}{*}{$\begin{array}{l}\text { Area } \\
89.27 \\
\end{array}$} & \multirow{2}{*}{$\begin{array}{c}\text { Time } \\
2.21 \\
\end{array}$} & \multirow{2}{*}{$\begin{array}{c}\text { Area } \\
0.78 \\
\end{array}$} & \multirow{2}{*}{$\begin{array}{c}\text { Time } \\
1.44 \\
\end{array}$} & \multirow{2}{*}{$\begin{array}{l}\text { Area } \\
51.26\end{array}$} \\
\hline $\mathrm{O}=\mathrm{C}=\mathrm{O}$ & Carbon dioxide & & & & & & \\
\hline & Water & 1.39 & 7.70 & - & - & - & - \\
\hline & Dimethyl ether & - & - & 1.73 & 7.96 & - & - \\
\hline & 2-Propenal & - & - & 2.36 & 0.27 & - & - \\
\hline & Acetic acid & - & - & 2.49 & 0.84 & - & - \\
\hline & 2-Propanone & - & - & 2.63 & 0.41 & 1.63 & 11.97 \\
\hline & $\begin{array}{l}\text { 2-Oxiranecarboxylic-3-methyl } \\
\text { acid }\end{array}$ & - & - & 2.87 & 0.16 & - & - \\
\hline & & & & & & & \\
\hline & 2-Butanone-3-hydroxy & - & - & 2.94 & 0.41 & - & - \\
\hline 0 & & & & & & & \\
\hline
\end{tabular}


Table 3. Cont

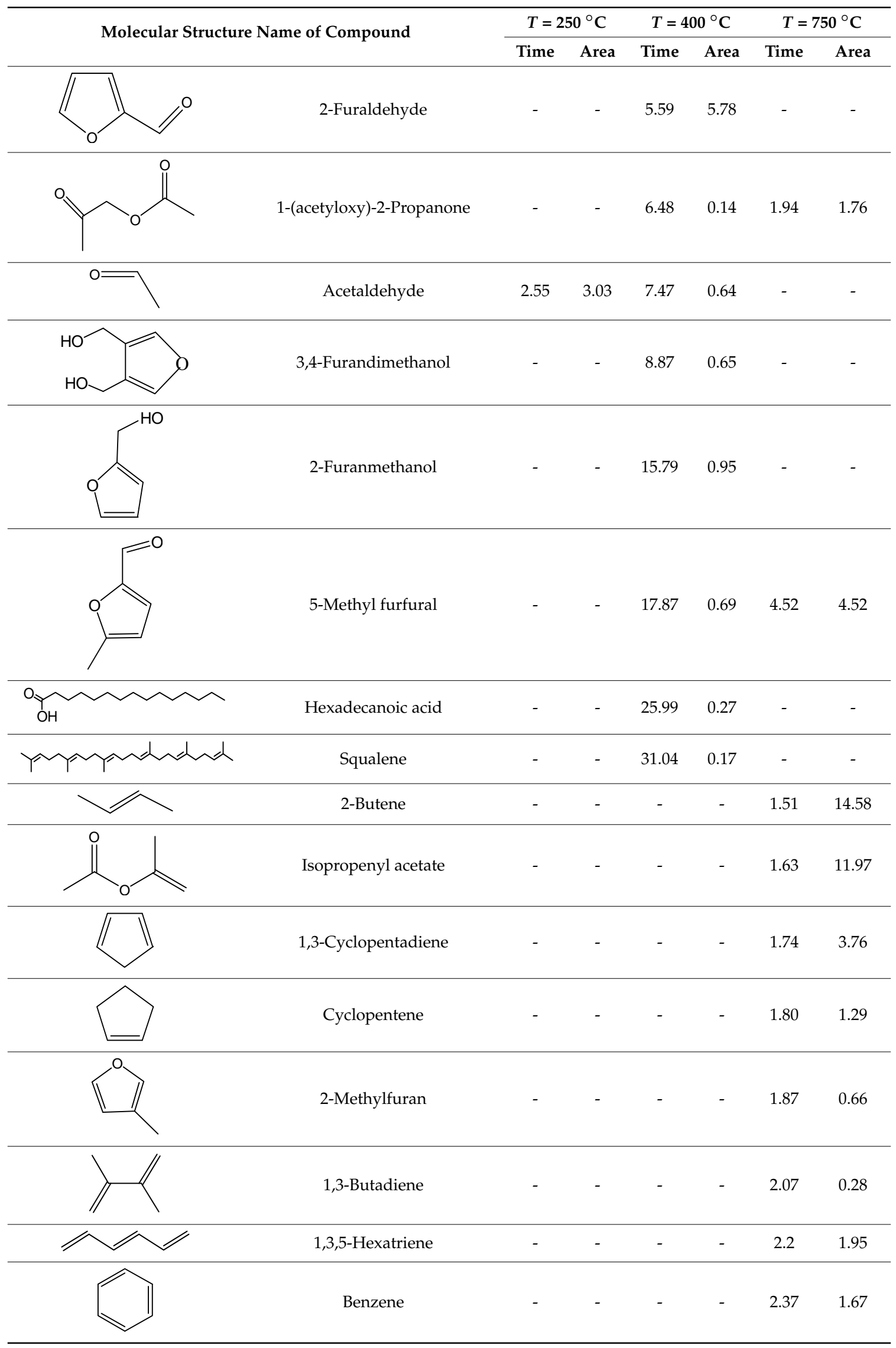


Table 3. Cont.

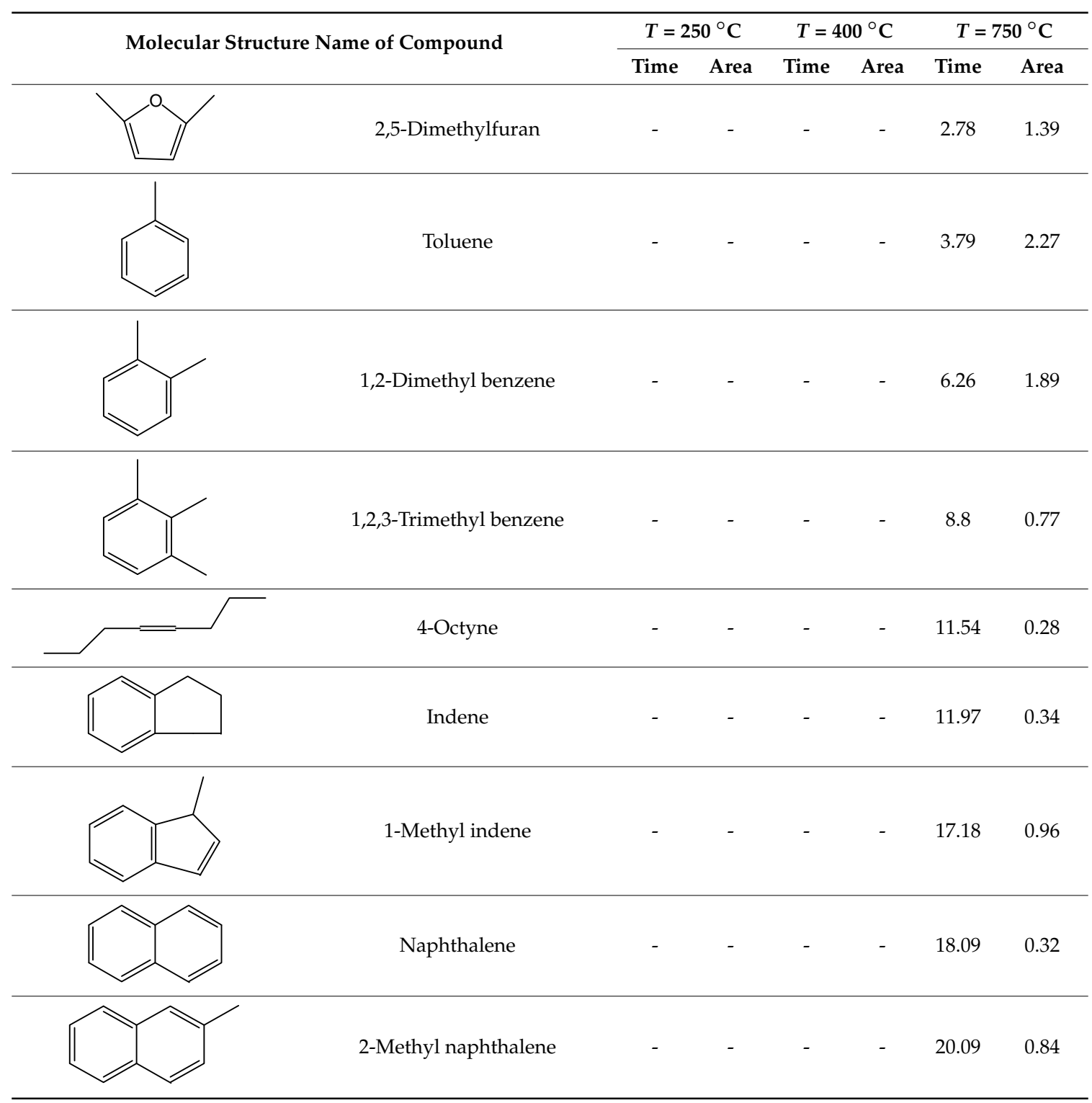

According to the analysis of Py-GC-MS, the proposed thermal degradation mechanism of $\mathrm{CAB}$ is shown in Figure 7. The main chain of $\mathrm{CA}$ was broken to produce $\mathrm{G}$ and $\mathrm{M}$ monomers at $400{ }^{\circ} \mathrm{C}$. The monomer was firstly esterified by releasing $\mathrm{H}_{2} \mathrm{O}$, followed by the ring-opening reaction of the intermediate products while losing some small molecules such as $\mathrm{H}_{2} \mathrm{O}, \mathrm{CO}$, etc., and lastly 2-propanone was formed in the pathway. On the other hand, the monomer was decarboxylated by releasing $\mathrm{CO}_{2}$. Subsequently, the reaction occurred as follows: (1) 2-furaldehyde was produced through tautomerization and cyclic hemiacetal and dehydration reactions after the cyclic fragmentation of 2,3,4,5-tetrahydroxypentanal; (2) 2,3-butanedione and acetic acid was generated by the loss of $\mathrm{H}_{2}$ and ethylene to 3-hydroxybutanone produced through the acetone acetate releasing $\mathrm{CO}$; and (3) 2-methylfuran and dimethyl ether was formed by vinyl propionate losing a series of small molecules. 


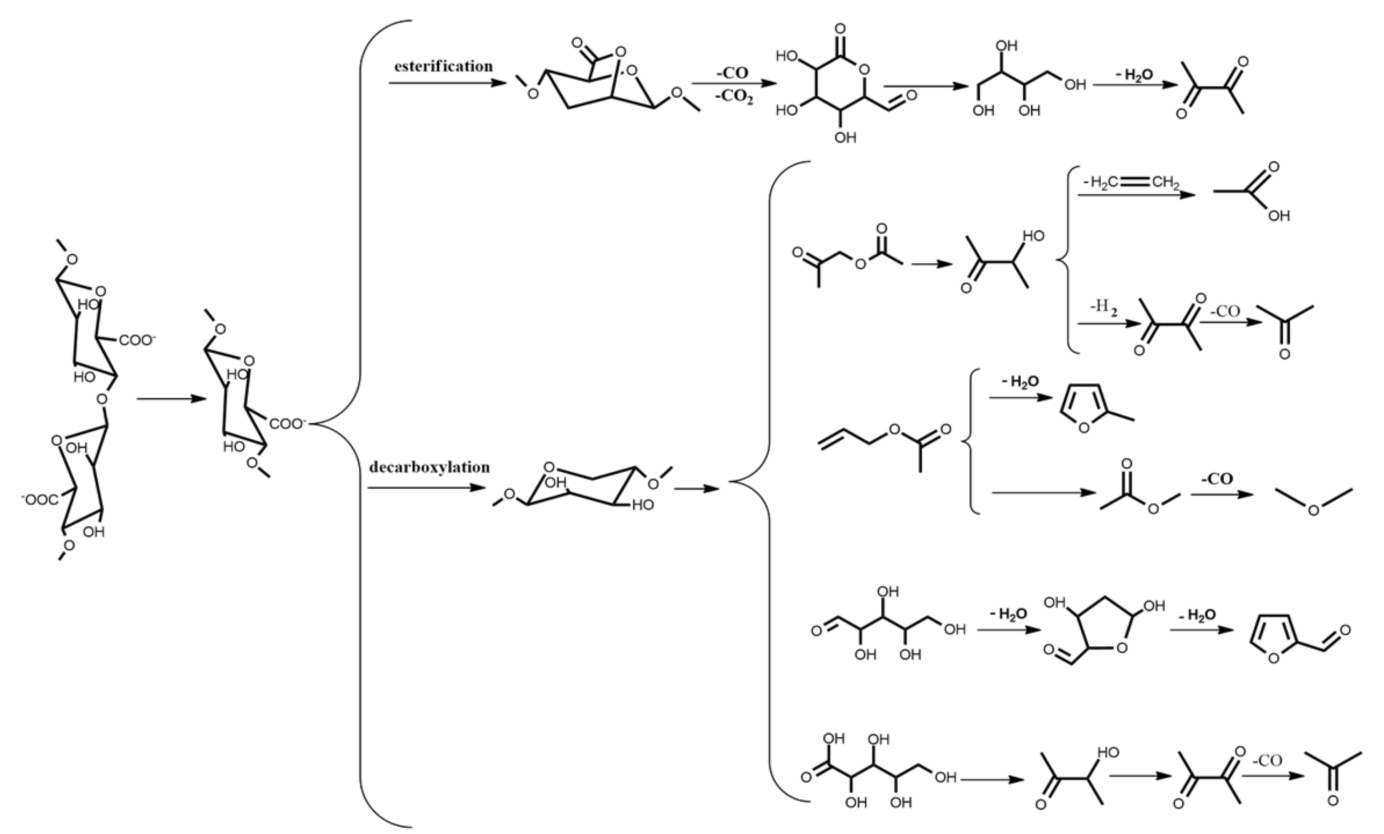

Figure 7. Proposed pyrolysis mechanism of CAB.

\section{Conclusions}

A type of hybrid composites based on calcium alginate and nano-borate particles was prepared by an in situ and post-cross-linking method, which was simple, eco-friendly, and economical. The combustion results indicated that the prepared composites possessed better thermal stability and flame-retardant properties. The inorganic nanoparticles can further suppress the flammability of the calcium alginate. Both nano-calcium borate and calcium alginate played crucial roles in improving the flame retardancy of $\mathrm{CAB}$ during combustion. The flame-retardant mechanism was proposed based on the experimental data, in which the calcium borate can cover the surface of calcium alginate, resulting in the decrease in the flame spread rate by forming barriers to prevent heat, oxygen, and smoke particles. The prepared materials show enormous potential to be applied in the building insulation materials and textile industry.

Author Contributions: Q.L. conceived and designed the experiments; Z.L. (Zhenhui Liu) and Z.L. (Zichao Li) performed the experiments; Q.L., X.Z. and L.Z., analyzed the data; Z.L. (Zhenhui Liu) and Z.L. (Zichao Li) wrote the paper.

Funding: This work was supported by the National Natural Science Foundation of China (grant number 51773102, 51503110), and Qingdao Postdoctoral Application Research Project (Grant Number 2015134).

Conflicts of Interest: The authors declare no conflict of interest.

\section{References}

1. Wang, Y.; De, S.; Yan, N. Rational control of nano-scale metal-catalysts for biomass conversion. Chem. Commun. 2016, 52, 6210-6224. [CrossRef] [PubMed]

2. Mu, B.; Wang, H.; Hao, X.; Wang, Q. Morphology, mechanical properties and dimensional stability of biomass particles/high density polyethylene composites: Effect of species and composition. Polymers 2018, 10, 308. [CrossRef]

3. Moniri, M.; Boroumand Moghaddam, A.; Azizi, S.; Abdul Rahim, R.; Bin Ariff, A.; Zuhainis Saad, W.; Navaderi, M.; Mohamad, R. Production and status of bacterial cellulose in biomedical engineering. Nanomaterials 2017, 7, 257. [CrossRef]

4. Chen, H.-B.; Wang, Y.-Z.; Sánchez-Soto, M.; Schiraldi, D.A. Low flammability, foam-like materials based on ammonium alginate and sodium montmorillonite clay. Polymer 2012, 53, 5825-5831. [CrossRef] 
5. Sato, K.; Tanaka, K.; Takata, Y.; Yamamoto, K.; Kadokawa, J. Fabrication of cationic chitin nanofiber/alginate composite materials. Int. J. Biol. Macromol. 2016, 91, 724-729. [CrossRef] [PubMed]

6. Liu, Y.; Zhao, X.-R.; Peng, Y.-L.; Wang, D.; Yang, L.; Peng, H.; Zhu, P.; Wang, D.-Y. Effect of reactive time on flame retardancy and thermal degradation behavior of bio-based zinc alginate film. Polym. Degrad. Stab. 2016, 127, 20-31. [CrossRef]

7. Liu, D.; Zhao, K.; Qi, M.; Li, S.; Xu, G.; Wei, J.; He, X. Preparation of protein molecular-imprinted polysiloxane membrane using calcium alginate film as matrix and its application for cell culture. Polymers 2018, 10, 170. [CrossRef]

8. Das, D.; Bang, S.; Zhang, S.; Noh, I. Bioactive molecules release and cellular responses of alginate-tricalcium phosphate particles hybrid gel. Nanomaterials 2017, 7, 389. [CrossRef] [PubMed]

9. Aimé, C.; Coradin, T. Nanocomposites from biopolymer hydrogels: Blueprints for white biotechnology and green materials chemistry. J. Polym. Sci. Part. B Polym. Phys. 2012, 50, 669-680. [CrossRef]

10. Lee, K.Y.; Mooney, D.J. Alginate: Properties and biomedical applications. Prog. Polym. Sci. 2012, 37, $106-126$. [CrossRef] [PubMed]

11. Liu, Y.; Zhang, C.J.; Zhao, J.C.; Guo, Y.; Zhu, P.; Wang, D.Y. Bio-based barium alginate film: Preparation, flame retardancy and thermal degradation behavior. Carbohydr. Polym. 2016, 139, 106-114. [CrossRef] [PubMed]

12. Zhao, K.; Zhang, X.; Wei, J.; Li, J.; Zhou, X.; Liu, D.; Liu, Z.; Li, J. Calcium alginate hydrogel filtration membrane with excellent anti-fouling property and controlled separation performance. J. Membr. Sci. 2015, 492, 536-546. [CrossRef]

13. Zhao, D.; Liu, C.J.; Zhuo, R.X.; Cheng, S.X. Alginate $/ \mathrm{CaCO}_{3}$ hybrid nanoparticles for efficient codelivery of antitumor gene and drug. Mol. Pharm. 2012, 9, 2887-2893. [CrossRef] [PubMed]

14. Googerdchian, F.; Moheb, A.; Emadi, R. Lead sorption properties of nanohydroxyapatite-alginate composite adsorbents. Chem. Eng. J. 2012, 200-202, 471-479. [CrossRef]

15. Su, C.-H.; Kumar, G.V.; Adhikary, S.; Velusamy, P.; Pandian, K.; Anbu, P. Preparation of cotton fabric using sodium alginate-coated nanoparticles to protect against nosocomial pathogens. Biochem. Eng. J. 2017, 117, 28-35. [CrossRef]

16. Carneiro-da-Cunha, M.G.; Cerqueira, M.A.; Souza, B.W.S.; Carvalho, S.; Quintas, M.A.C.; Teixeira, J.A.; Vicente, A.A. Physical and thermal properties of a chitosan/alginate nanolayered PET film. Carbohydr. Polym. 2010, 82, 153-159. [CrossRef]

17. Kim, J.H.; Park, S.; Kim, H.; Kim, H.J.; Yang, Y.H.; Kim, Y.H.; Jung, S.K.; Kan, E.; Lee, S.H. Alginate/bacterial cellulose nanocomposite beads prepared using Gluconacetobacter xylinus and their application in lipase immobilization. Carbohydr. Polym. 2017, 157, 137-145. [CrossRef] [PubMed]

18. Jouannin, C.; Vincent, C.; Dez, I.; Gaumont, A.C.; Vincent, T.; Guibal, E. Study of alginate-supported ionic liquid and Pd catalysts. Nanomaterials 2012, 2, 31-53. [CrossRef] [PubMed]

19. Liu, Y.; Li, Z.; Wang, J.; Zhu, P.; Zhao, J.; Zhang, C.; Guo, Y.; Jin, X. Thermal degradation and pyrolysis behavior of aluminum alginate investigated by TG-FTIR-MS and Py-GC-MS. Polym. Degrad. Stab. 2015, 118, 59-68. [CrossRef]

20. Serrano-Aroca, A.; Ruiz-Pividal, J.F.; Llorens-Gamez, M. Enhancement of water diffusion and compression performance of crosslinked alginate films with a minuscule amount of graphene oxide. Sci. Rep. 2017, 7, 11684. [CrossRef] [PubMed]

21. Papageorgiou, S.K.; Kouvelos, E.P.; Favvas, E.P.; Sapalidis, A.A.; Romanos, G.E.; Katsaros, F.K. Metal-carboxylate interactions in metal-alginate complexes studied with FTIR spectroscopy. Carbohydr. Res. 2010, 345, 469-473. [CrossRef] [PubMed]

22. Llorens-Gámez, M.; Serrano-Aroca, Á. Low-cost advanced hydrogels of calcium alginate/carbon nanofibers with enhanced water diffusion and compression properties. Polymers 2018, 10, 405. [CrossRef]

23. Zhang, J.; Ji, Q.; Shen, X.; Xia, Y.; Tan, L.; Kong, Q. Pyrolysis products and thermal degradation mechanism of intrinsically flame-retardant calcium alginate fibre. Polym. Degrad. Stab. 2011, 96, 936-942. [CrossRef]

24. Chen, H.B.; Shen, P.; Chen, M.J.; Zhao, H.B.; Schiraldi, D.A. Highly efficient flame retardant polyurethane foam with alginate/clay aerogel coating. ACS Appl Mater. Interfaces 2016, 8, 32557-32564. [CrossRef] [PubMed] 
25. Li, J.; Li, Z.; Zhao, X.; Deng, Y.; Xue, Y.; Li, Q. Flame retardancy and thermal degradation mechanism of calcium alginate $/ \mathrm{CaCO}_{3}$ composites prepared via in situ method. J. Therm. Anal. Calorim. 2017, 131, 2167-2177. [CrossRef]

26. Ko, Y.G.; Choi, U.S. Diverse applications of fibers surface-functionalized with nano- and microparticles. Compos. Sci. Technol. 2013, 79, 77-86. [CrossRef]

27. Ngo, Y.H.; Li, D.; Simon, G.P.; Garnier, G. Paper surfaces functionalized by nanoparticles. Adv. Colloid Interface Sci. 2011, 163, 23-38. [CrossRef] [PubMed]

28. Voisin, H.; Bergstrom, L.; Liu, P.; Mathew, A.P. Nanocellulose-based materials for water purification. Nanomaterials 2017, 7, 57. [CrossRef] [PubMed]

29. Tian, Y.; He, Y.; Yu, L.; Deng, Y.; Zheng, Y.; Sun, F.; Liu, Z.; Wang, Z. In situ and one-step synthesis of hydrophobic zinc borate nanoplatelets. Colloids Surf. Physicochem. Eng. Aspects 2008, 312, 99-103. [CrossRef]

30. Geng, Y.-J.; Liu, Z.-H. Preparation and thermodynamic characterization of $2 \mathrm{CaO} \cdot \mathrm{B}_{2} \mathrm{O}_{3} \mathrm{H}_{2} \mathrm{O}$ nanomaterials with enhanced flame retardant properties. Colloids Surf. Physicochem. Eng. Asp. 2017, 522, 563-568. [CrossRef]

31. Zhu, W.; Zhang, X.; Wang, X.; Zhang, H.; Zhang, Q.; Xiang, L. Short belt-like $\mathrm{Ca}_{2} \mathrm{~B}_{2} \mathrm{O}_{5} \cdot \mathrm{H}_{2} \mathrm{O}$ nanostructures: Hydrothermal formation, FT-IR, thermal decomposition, and optical properties. J. Cryst. Growth 2011, 332, 81-86. [CrossRef]

32. Lewin, M. Some comments on the modes of action of nanocomposites in the flame retardancy of polymers. Fire Mater. 2003, 27, 1-7. [CrossRef]

33. Liu, Z.-H.; Xue, L. Preparation of nanoplates assembled $4 \mathrm{CaO} \cdot 5 \mathrm{~B}_{2} \mathrm{O}_{3} \cdot 7 \mathrm{H}_{2} \mathrm{O}$ oval-like microspheres via a hydrothermal method. Mater. Lett. 2008, 62, 2692-2695. [CrossRef]

34. Attia, N.F. Organic nanoparticles as promising flame retardant materials for thermoplastic polymers. J. Therm. Anal. Calorim. 2016, 127, 2273-2282. [CrossRef]

35. Chen, W.; Liu, Y.; Liu, P.; Xu, C.; Liu, Y.; Wang, Q. The preparation and application of a graphene-based hybrid flame retardant containing a long-chain phosphaphenanthrene. Sci. Rep. 2017, 7, 8759. [CrossRef] [PubMed]

36. Wang, S.; Tang, Y.; Schobert, H.H.; Guo, Y.N.; Gao, W.; Lu, X. FTIR and simultaneous TG/MS/FTIR study of Late Permian coals from Southern China. J. Anal. Appl. Pyrolysis 2013, 100, 75-80. [CrossRef]

37. Wu, S.; Shen, D.; Hu, J.; Xiao, R.; Zhang, H. TG-FTIR and Py-GC-MS analysis of a model compound of cellulose-glyceraldehyde. J. Anal. Appl. Pyrolysis 2013, 101, 79-85. [CrossRef]

38. Shi, R.; Tan, L.; Zong, L.; Ji, Q.; Li, X.; Zhang, K.; Cheng, L.; Xia, Y. Influence of $\mathrm{Na}^{(+)}$and Ca ${ }^{(2+)}$ on flame retardancy, thermal degradation, and pyrolysis behavior of cellulose fibers. Carbohydr. Polym. 2017, 157, 1594-1603. [CrossRef] [PubMed]

39. Liu, Y.; Zhao, J.-C.; Zhang, C.-J.; Cui, L.; Guo, Y.; Zhu, P.; Zhang, H.; Zheng, Z.-W.; Wang, D.-Y. Flame retardancy and thermal degradation properties of cotton/alginate fabric. J. Therm. Anal. Calorim. 2016, 127, 1543-1551. [CrossRef]

40. Zhang, J.; Ji, Q.; Zhang, P.; Xia, Y.; Kong, Q. Thermal stability and flame-retardancy mechanism of poly (ethylene terephthalate)/boehmite nanocomposites. Polym. Degrad. Stab. 2010, 95, 1211-1218. [CrossRef] 